\title{
SYSTEMIC ASSESSMENT AND ANALYSIS OF FACTORS AFFECT THE RELIABILITY OF A WIND TURBINE
}

\author{
Pantelis N. Botsaris* \\ Democritus University of Thrace School of Engineering, Xanthi, Greece \\ E. I. Konstantinidis \\ Democritus University of Thrace School of Engineering, Xanthi, Greece \\ D. Pitsa \\ Democritus University of Thrace School of Engineering, Xanthi, Greece
}

Nowadays, the availability of wind turbines usually approaches the $98 \%$. The objective is to increase the turbines availability, by improving the wind turbine reliability especially for offshore plants. The wind turbines reliability is a pivotal factor in the successfully function of a wind power plant. High reliability can be achieved by understanding and minimizing the failures of the system. Maintenance planning could make maintenance more efficient and could lead to a reduction of failure events. In order to decide the most effective maintenance strategy, it should be identified the most critical components of the wind turbines, which are prone to failures. The maintenance strategy should take into both the reliability improvement and the reduction of maintenance cost. Moreover, it is essential to determine and record the main cause that provokes the failure event. The data logging and statistical processing of failure information could improve the reliability of the system components. A wind turbine is a complex power generating system consisting of several structural, electrical and mechanical components. Its efficiency depends largely on its reliability level.

In the present study, the factors that affect the reliability of a wind turbine are presented, as well as the analytical way of calculating its reliability. The reliability analysis of the wind turbine is based on the systemic approach of the wind turbine subsystems, as its total reliability depends directly on the reliability of the subsystems. Moreover, it is based on a technical analysis of the reliability of complex systems. The model used is the Fault Tree Analysis (FTA), which is an identification method for probable causes of system failure. The relation of reliability, maintainability and availability is also presented and explained by the example of a small wind farm.

Keywords: Wind turbines, systems, reliable, plants, maintenance, failure, availability

\section{INTRODUCTION}

Continuing population growth and the effort to improve the standards of living lead to an increasing energy demand globally. The energy needs are met by conventional energy sources which are based on fossil fuel resources. The latter however, take billions of years to compose and are consumed faster than nature produces them. Furthermore, they emit harmful gases (NOx, SOx etc) when used, causing severe damages on human health and the environment. Consequently, even though the conventional energy sources have largely contributed to the economic development and improvement of the standard of living, the need of increasing the use of renewable energy sources in the energy balance of each country has become imperative. Surely, green growth should not be perceived as a turn to an irrational and at any cost use of renewable energy sources, but as an investment in politics and technologies which would turn renewable energy into competitive and sustainable energy sources.

A renewable energy source that is used for the production of electrical power is wind power, i.e. the kinetic energy of the wind. The energy production of a wind farm (group of wind turbines) depends largely on its reliability, meaning the reliability of each individual wind turbine of which it consists. 
Nowadays wind power generation plays an increasingly important role in the global energy market. Only during the year 2009 the globally installed wind power capacity has reached $38 \mathrm{GW}$. Fig. 1 shows the globally installed wind power capacity from 1996 to 2009 [06]. To achieve the best possible power production efficiency of the installed wind turbine, a high reliability level should be reached. The subject of this study is to determine the reliability of a wind turbine and the factors that affect it.

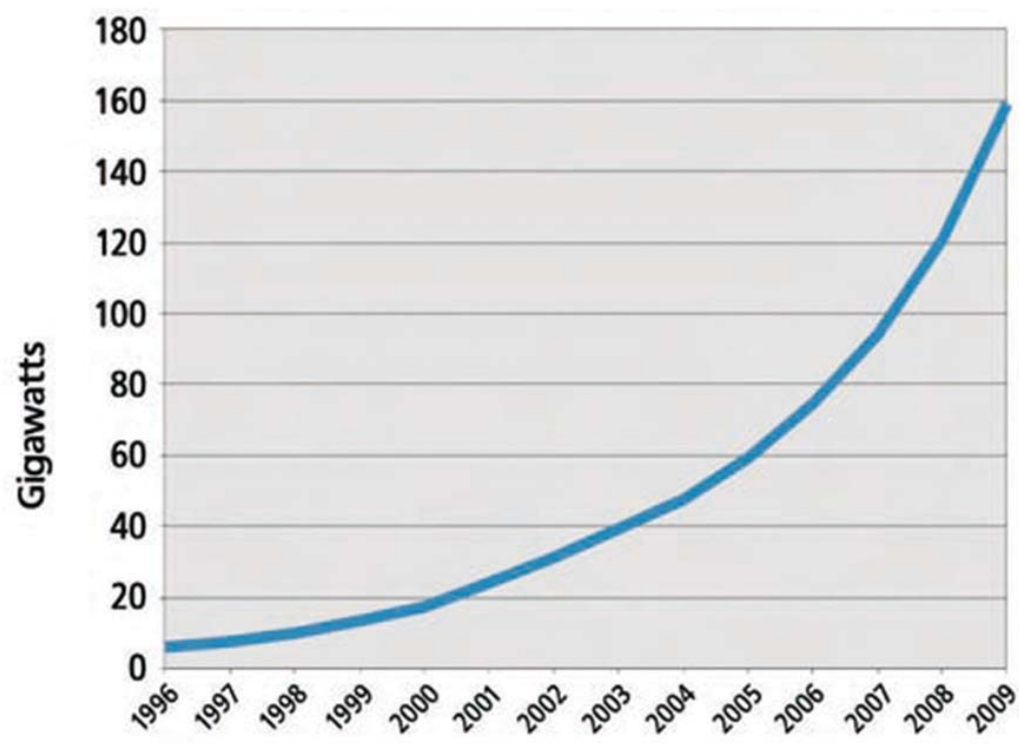

Figure 1: Globally installed wind power capacity [01]

\section{SYSTEMIC APPROACH}

The system of reference, i.e. the system examined here, is the wind turbine. The hypersystem is the wind farm and the subsystems are its components, such as the rotor, the nacelle, the tower and the foundation as Fig. 2 presents.

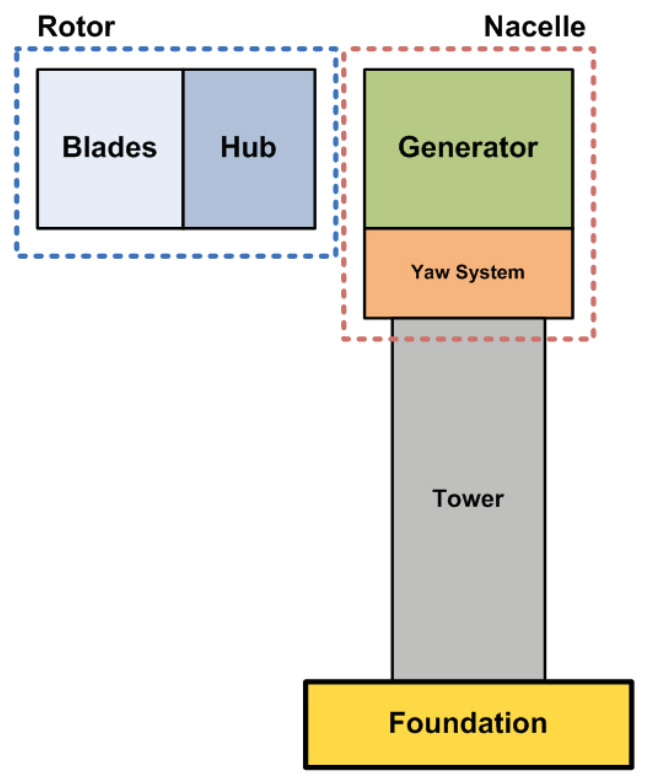

Figure 2: A wind turbine system
The operation of a wind farm is assured when at least one of its wind turbines runs. The wind turbines are connected in parallel arrangement and its subsystems in series arrangements. The calculation of the wind farm reliability is based on the calculation of the reliability of its wind turbines, as it will be described next.

The issue of the wind turbines reliability level is of great importance for the wind farm operators. The main goal of a wind farm operator is the increase of the produced energy in order to achieve the highest possible profit. This can be reached by improving either the reliability of the wind turbines or their maintenability or both, if this is possible. This way the maintenance expenses are reduced, resources are saved and the availability increases.

The purpose of the present study is to determine the factors that affect the reliability of a wind turbine and the evaluation method. In order to propose solutions capable to improve the reliability of a wind turbine, one should first determine the factors that influence its reliability and at the same time a quantitative reliability analysis should be conducted. By calculating the reliability it is possible to determine the degree of influence of the 
corrective action proposed, which will be based on the factors that affect it. If the proposed corrective action highly increases reliability, it can be selected as a solution to the problem of low reliability. At the present study no specific proposals for the reliability improvement are made, but general directions to be followed in order to improve the reliability of a wind turbine are suggested.

The main factor that influences the reliability of a wind turbine is the capability of its subsystems to fulfill their proper function without frequent failures. By detecting the critical subsystems of a wind turbine, i.e. the subsystems with the highest failure rate $(\lambda)$ and the primary causes of their failure, increase of reliability can be achieved. To determine the critical subsystems and their primary failures, these should be first located and described adequately. Then, a detection of the possible failures of the subsystems should follow using a reliability analysis method. Based on this analysis the reliability of the subsystems and the total reliability of the wind turbine are calculated. There are several analysis methods for complex systems such as the Failure Mode Effect Analysis / Failure Mode Effect and Criticality Analysis, the Event Tree Analysis, the Generic Parts Count Analysis and the Fault Tree Analysis. A fault tree shows graphically the logical connection between a specific type of failure and the main causes of the failure (hierarchical structure of error).

The reliability of a wind turbine does not depend exclusively on the reliability of its subsystems, but also on external, indirect factors like the maintenance strategy used, the existence of spare parts, the time needed to repair, the existence of control systems of the subsystems, the type of wind turbine related to the operational environment (onshore, nearshore, offshore) and the training of the personnel. In the present study these factors that affect the reliability of a wind turbine will not be further analyzed.

\section{WIND TURBINE SUBSYSTEMS}

In this part the subsystems of a horizontal axis wind turbine are briefly presented as well as their subsystems. Even though the brief presentation of the subsystem would preferably be in the form of a tree in order to gain a better visual perception of the subsystems and a clearer understanding of their structure, this cannot be done due to the large number of the subsystems and the limited space. In fig.2 a typical horizontal wind turbine axis and its subsystems (rotor, nacelle, tower and foundation) are presented. The main subsystems of a wind turbine are:

$$
\begin{array}{ll}
\text { 1. } & \text { Rotor } \\
\text { - } & \text { Blades } \\
\text { - } & \text { Hub } \\
\text { - Nose cone/spinner } \\
\text { - } \text { Pitch regulation system }
\end{array}
$$

\section{Nacelle}

- Drive train

- Couplings

- Mechanical brain

- Hydraulic systems

- Generator

- Machine support frame

- Nacelle cover/enclosure

- Yaw system

\section{Tower}

4. Foundation

\section{Control system}

- Sensors

- Actuators

- System consisting of hardware and software

\section{WIND TURBINE AVAILABILITY AND FACTORS THAT AFFECT IT}

Reliability $(R)$ is the probability of a system or a component to perform and maintain its required functions without failures for a specified period of time when this operates according to its specifications under stated conditions. So, a system is considered to be reliable when it successfully accomplishes its mission without failing, i.e., without undergoing any damages. But even the best possible design, the best possible manufacturing and the best possible maintenance of a system, cannot eliminate the failure possibility. Nevertheless, the effort to avoid failure as much as possible is necessary, in order to achieve the highest level of reliability. Moreover, in systems where maintenance strategies like corrective maintenance are applied, the reliability of a component or a whole system is not the primary aim. On the contrary, concepts like probability of 
failure occurrence, failure rate and maintenance rate are important for defining other concepts related to reliability, such as availability and maintainability.

Availability of a system or subsystem is the proportion of time a system is in the functioning condition for which it was designed. Furthermore, maintainability is of great importance for this kind of system, meaning the probability of performing a successful repair action within a given time (downtime). The technical characteristics, that are the design and function of the wind turbine subsystems, directly affect its reliability and consequently the reliability of the whole wind farm. For this reason the wind turbine subsystems have to be reliable and frequent failures must be avoided. Information related to a wind farm reliability can be drawn by analyzing the failure data, which can lead to redesigning a component or changing the maintenance strategy. But finding this kind of information on the wind turbine failures in order to statistically analyze it has proved to be quite difficult. Often these failure data are not reported in detail by the wind farm personnel, or are not provided by the wind turbine manufacturers. Even in cases where the information is provided, data from different wind farms cannot be compared to each other, due to the different design of the wind turbines.

The analytical report of subsystem failures is necessary in order to optimize the reliability of a wind turbine. To determine the failures it is necessary to understand the way a wind turbine functions and the interaction between the individual subsystems [02]. Based on the statistical data the less reliable subsystems can be detected and focused on. The subsystems which have the highest failure frequency (in descending order) are: the electrical system (the equipment needed for transportation and control of electrical power from the generator to the grid), the rotor (blades and hub), the generator, the hydraulic systems and the gear box, according to Costinas and al [02] The conclusions drawn by a failure statistical analysis of one particular wind turbine do not apply for any wind turbine, because the possible failures that can occur in a wind turbine depend on different parameters and factors, such as the model of the wind turbine, the size, the maintenance strategy which is used, the operating environment etc. The criterion to consider a subsystem as critical is the duration of the time the wind turbine is out of function due to subsystem failure. Determining the critical subsystems of a wind turbine is the first step to improve the reliability of the whole system.

\section{FAULT TREE ANALYSIS}

There are several methods for analyzing the reliability of a complex system such as the Generic Parts Count Analysis, the Failure Mode Effect and Criticality Analysis, the Event Tree Analysis and the Fault Tree Analysis. The Fault Tree Analysis was selected in this present study and it has been used to analyze the reliability of a wind turbine. More specifically, in this unit the fault tree of the nacelle of a typical horizontal axis wind turbine is presented, since this is the subsystem that includes more mechanical and electrical parts than any other subsystem. Based on this analysis the primary faults that can lead to a total failure of a nacelle and therefore of the whole wind turbine can be detected. By optimizing the reliability of the nacelle parts in which the primary faults are located, their failure rate decreases, thus improving the nacelle and consequently the total wind turbine reliability. The wind turbine reliability calculation method is presented below, based on a fault tree analysis and follows the example of an assessment of the reliability and availability of a small wind farm consisting of six similar wind turbines.

Setting as a top event the power production failure by a single wind turbine, the wind turbine fault tree analysis is presented below. Other possible causes that can lead to power production failure such as weather conditions, are not our concern in the present study, therefore they are not taken into account. Wind turbine failures related to subsystems failure only are examined, such as failure of the rotor, the nacelle, the tower and the foundation. The fault tree analysis is applied in a typical wind turbine Bonus $600 \mathrm{KW}$. The subsystems which the fault tree analysis refer to, is the drive train system, the generator, the yaw system. Also the fault tree analysis describes possible failures of each subsystem in detail and by looking at the tree one can perceive the total of the subsystems the wind turbine consists of. In figures 3.1 and 3.2 the fault tree analysis of a Bonus $600 \mathrm{KW}$ wind turbine is presented. Because of the extended size of the fault tree only a small part of it is presented below.

Data for the possible failures of the nacelle were taken from the data base of the ROKAS S.A. and the international bibliography [02, 04, 07]. 
Studying the tree one can immediately recognize the possible primary faults that can lead to a nacelle failure and consequently to a wind turbine failure. Detecting the primary faults is the first step to determine the parameters of the subsystem failure probability.

This way, for example, in fig. 3.2 the probability of poor quality of lubrication oil occurrence $P(F 0)$ (main event) could be calculated using the probability theory and the existence of failure data base (distributions):

$P(F 3)=P(F 1)+P(F 2)-P(F 1) P(F 2)$

$P(F O)=1-[1-P(F 3)][1-P(F 4)][1-P(F 5)]$
$P(F i)$ the probability of failure $F i$ occurrence with $i=1,2, . .5$ (1:Leakage/cracks on air cooler, 2: Rusty cooling fins of the radiator, 3:Oil cooler failure, 4:Not regular change of oil, 5: Oil filter failure)

To optimize the reliability the primary faults have to be reduced and this can be achieved in different ways, either by increasing the reliability of the subsystems where failure occurs (for example, by redesigning them) or by improving the maintenance of the subsystems or by installing monitoring systems to control the situation of the critical subsystems etc.

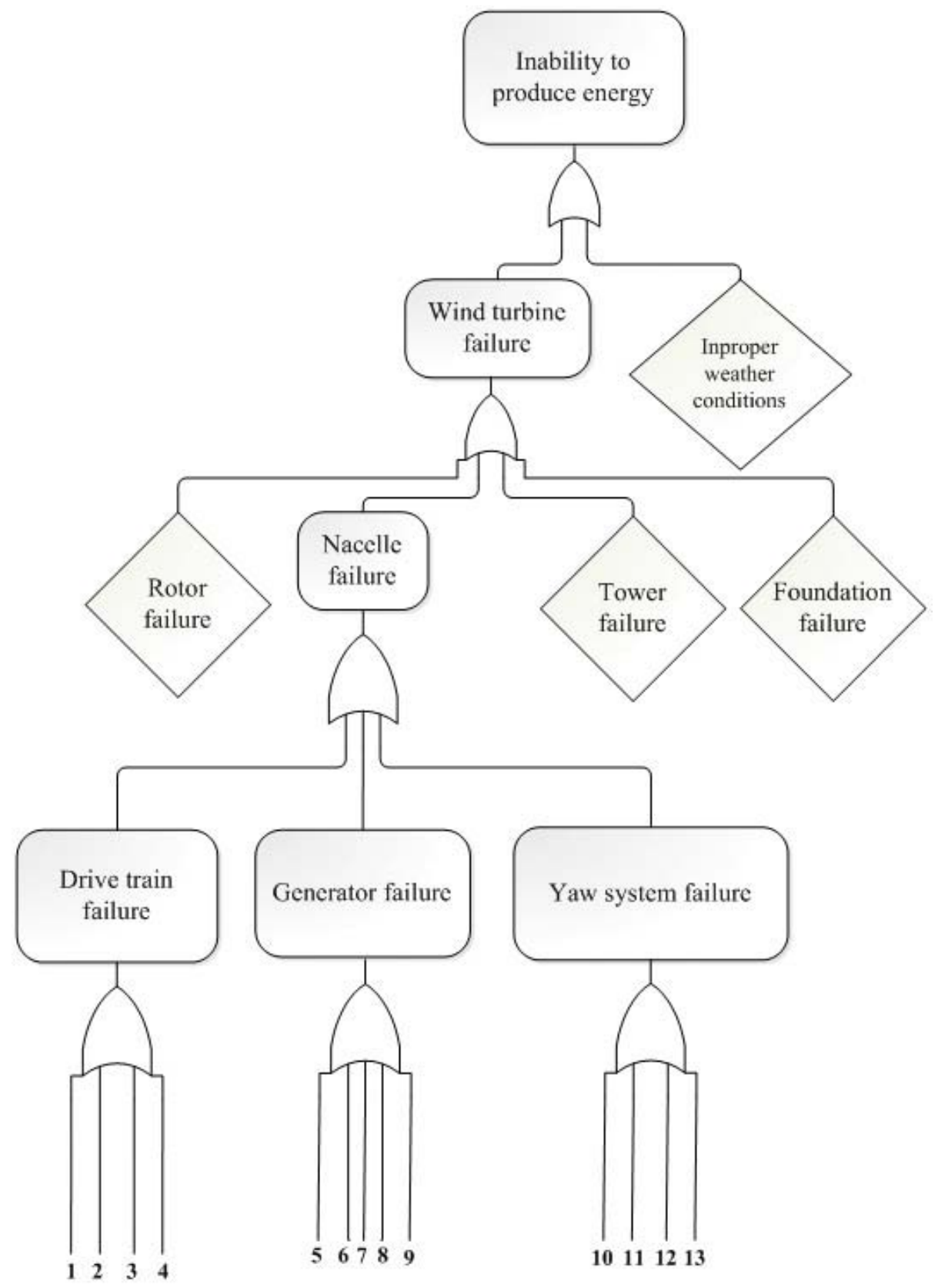

Figure 3.1: Fault tree of main subsystems 


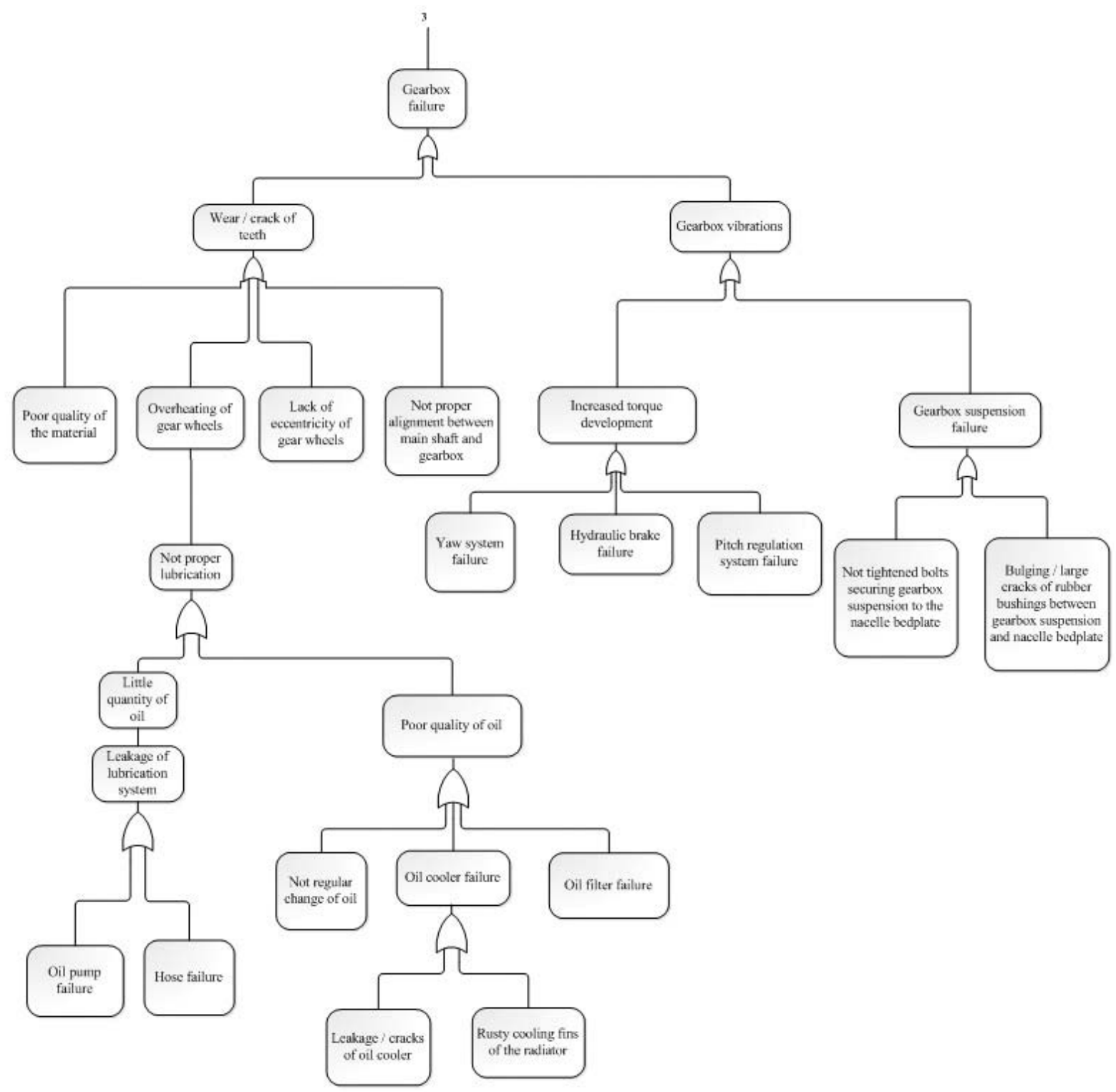

Figure 3.2: Fault tree of the gearbox subsystem

The analysis and setting of the subsystems reliability parameters following the fault tree analysis could help to compose the mathematical model of the total wind turbine reliability.

An example of the calculation of the reliability and availability of a small wind farm consisting of 6 wind turbines is presented below, based on the reliability, maintenability and availability of each individual wind turbine. The failure data were taken from German wind farms [07]. The data of this research concern the period of time 20032004 and refer to 483 wind turbines and 3175 reported failures. They are related to failure rates specifically of the main wind turbine subsystems. Table 1 presents the calculated failure rate and the reliability of each subsystem based on the exponential distribution. The wind turbines were considered to be identical to each other for the calculations. The probability of failure occurrence in wind turbine $n$, with $n=1 \ldots 6$, is:

$\mathrm{R}_{\mathrm{WTn}}=\mathrm{R}_{\text {hub }} \times \mathrm{R}_{\text {blades/pitch regulation system }} \times \mathrm{R}_{\text {generator }} \times \mathrm{R}_{\text {electrical system }} \times \mathrm{R}_{\text {control system }} \times \mathrm{R}_{\text {drive train }} \times \mathrm{R}_{\text {sensors }} \times$ $\times \mathrm{R}_{\text {gearbox }} \times \mathrm{R}_{\text {mechanical brakes }} \times \mathrm{R}_{\text {hydraulic systems }} \times \mathrm{R}_{\text {yaw system }} \times \mathrm{R}_{\text {structure }}$

In systems arranged in series the total reliability of the system (wind turbine) is equal to the product of the reliability values of each individual subsystem i.e.:
$R_{s}=R_{1} R_{2} \ldots . . R_{n}$

If we consider that the failure rates $\lambda i$ of the subsystems are constant and follow the exponent 
Table 1: Failure rates and wind turbine subsystems reliability

\begin{tabular}{|c|c|c|}
\hline \multicolumn{1}{|c|}{ Subsystem } & Failure rate (Nr/year) & Reliability \\
\hline Hub & 0,11 & 0,895 \\
\hline Blades/Pitch Regulating System & 0,17 & 0,843 \\
\hline Generator & 0,10 & 0,904 \\
\hline Electrical System & 0,55 & 0,576 \\
\hline Control System & 0,41 & 0,663 \\
\hline Drive Train & 0,05 & 0,951 \\
\hline Sensors & 0,24 & 0,786 \\
\hline Gearbox & 0,10 & 0,904 \\
\hline Mechanical Brake & 0,13 & 0,878 \\
\hline Hydraulic Systems & 0,23 & 0,794 \\
\hline Yaw System & 0,18 & 0,835 \\
\hline Structure & 0,09 & 0,913 \\
\hline Total & $\lambda_{\mathrm{s}}=2,38$ & $\mathrm{R}_{\mathrm{WTn}}=\mathrm{R}_{\mathrm{n}}=0,093$ \\
\hline
\end{tabular}

contribution, the total failure rate of the system (wind turbine) can be calculated by the following correlation:

$\lambda_{i}=\lambda_{1}+\lambda_{2}+\ldots .+\lambda_{n}$

In the failure data base of Ribrant study $/ 6 /$, it was estimated that in the time period 2003 $2004,3.174$ failures were reported and the total downtime of the wind turbines was 1010,5 hours or 0,318 hours/failure, which is the mean time to repair MTTR.

According to the systems theory the mean time until a failure occurs in a series system is equal to the ratio of the sum of the failure rates of the separate subsystems:

$M_{T T F}=1 /\left(\lambda_{1}+\lambda_{2} \ldots+\lambda_{n}\right)$

So, according to the correlation 4) the MTTF of a single wind turbine of the wind farm in the present study is equal to 0,420 hours.

The wind turbines in a wind farm are connected in a parallel arrangement. So, the reliability of the wind farm which consists of six wind turbines is given by:

$$
\begin{aligned}
R_{\text {wind farm }} & =1-\left(1-R_{\text {Wind Turbine } 1}\right) \times\left(1-R_{\text {wT2 }}\right) \times \ldots \times\left(1-R_{\text {WT }}\right)= \\
& =0,444=44,4 \%
\end{aligned}
$$

The availability of a single wind turbine $\mathrm{A}_{\mathrm{WTn}}$, with $\mathrm{n}=1,2 \ldots 6$, is $/ 7 /$ :

$\mathrm{A}_{\mathrm{WTn}}=\frac{M T T F}{M T T F+M T T R}=\frac{0,420}{0,420+0,318}=0,57=57 \%$
The availability of the whole wind farm Awind farm is given by:

$$
\begin{aligned}
A_{\text {wind farm }} & =1-\left(1-A_{W T 1}\right) \times\left(1-A_{W T 2}\right) \times \ldots . . \times\left(1-A_{W T d}\right)= \\
& =0,993=99,3 \%
\end{aligned}
$$

This example clearly shows that the reliability of a wind farm based on real statistical data is low, as there is a significant declination from $100 \%$ (ideal situation). Nevertheless, its availability is very high. This can be attributed to the fact that the repair time is short (MTTR) and to the type of connection (parallel) of the wind turbines within the wind farm. Of course, the effort to optimize the reliability of a wind turbine is necessary and should be continued on the field of design, development and operation of the wind turbines in order to save resources during their operation in maintenance free intervals.

\section{CONCLUSION}

The present study is a first and important step to the direction of analyzing and optimizing the reliability of a wind turbine. The parameters that affect the wind turbine reliability were examined, focusing on the reliability of the individual subsystems. By analyzing the reliability of the nacelle of a wind turbine using the fault tree analysis, the possible failures of the nacelle subsystems and the primary causes of these failures were determined. Moreover, the calculation of the subsystems reliability and the total wind turbine reliability was presented, based on the fault tree analysis. 
This study contributes to the research of the wind turbines reliability improvement. The followings are proposed as topics for further study:

1. The completion of the fault tree analysis of all the wind turbines subsystems

2. The application of an assessment method ANOVA type, in order to examine the importance of the different failures and classify them, for example, according to the rate of occurrence or repair. Such a research would require an up-to-date failure data base.

3. The precise calculation of the reliability of the wind turbine subsystems (determination of parameters by using contributions) and the determination of the mathematical model of the whole wind turbine. An up-to-date failure data base would be necessary in this case too.

4. Specific suggestions for the optimization of the wind turbine reliability and evaluation of the degree of improvement after their application.

5. Examination of the possibility of maintenability improvement with the prospect to minimize the mean time to repair the failures of the critical subsystems that have resulted from proposal 2 (failure assessment methods).

\section{ACKNOWLEDGEMENTS}

The authors wish to thank ROKAS S.A. for providing valuable information regarding the technical characteristics and access to the failure data base of their wind turbines.

\section{REFERENCES}

1) Al-Ahmar, E., Benbouzid1, M. E. H. and Turri, S. (2008), Wind Energy Conversion Systems Fault Diagnosis Using Wavelet Analysis, International Review of Electrical Engineering, 3 (4), 646-652.

2) Costinas, S., Diaconescu, I. and Fagarasanu, I. (2009), Wind Power Plant Condition Monitoring, Proceedings of the 3rd WSEAS International Conference on Energy Planning, Energy Saving, Enviromental Education, pp. 71-76, La Laguna, Tenerife, Canary Islands, Spain.

3) Danikas, M. G. and Karlis, A. (2011), A Review on Electrical Machines Insulation Aging and its Relation to the Power Electronics Arrangements with Emphasis on Wind Turbine Generators, Renewable and Sustainable Energy Reviews, 15 (4), 1748-1752.

4) Hameed, Z., Hong, Y. S., Cho, Y. M., Ahn, S. H. and Song, C. K. (2009), Condition Monitoring and Fault Detection of Wind Turbines and Related Algorithms: A Review, Renewable and Sustainable Energy Reviews, 13 (1), 1-39

5) Komarov D., Stupar S., Posteljnik Z., Review of the current wind energy tehnologies and global market, Journal of Applied Engineering Science, 9(2011)4, p.437-448.

6) REN21 (2010), Renewables 2010 Global Status Report, REN21.

7) Ribrant, J. (2006), Reliability Performance and Maintenance - A Survey of Failures in Wind Power Systems, Master Thesis at KTH School of Electrical Engineering, Supervisor: Bertling, L

8) Wessels, W. (2010), Practical Reliability Engineering and Analysis for System Design and Life-Cycle Sustainment, CRS Press, ISBN 978-1-4200-9439-8.

Paper sent to revision: 30.05 .2012

Paper ready for publication: 21.06.2012. 